\title{
Interferon-gamma ELISPOT for the screening and diagnosis of latent tuberculosis infection in healthy population of China*
}

\author{
Yi Peng ${ }^{1 \#}$, Fangfang Yang ${ }^{1 \#}$, Lin Zhou ${ }^{2}$, Meigui Zhao ${ }^{3}$, Yan Li ${ }^{1}$, Yuhong Huang ${ }^{1}$, Juan Wang ${ }^{1}$, \\ Lirong Huang ${ }^{1}$, Dan Xie ${ }^{1,4}$, Zhiquan Tu', Weiling Lin ${ }^{1,4}$, Jinhong Liu ${ }^{3 \dagger}$, Qiu Zhong ${ }^{2 \dagger}$, Xiaomin Lai ${ }^{1 \dagger}$ \\ ${ }^{1}$ Department of Microbiology, Ministry of Education Key Laboratory of Tropical Diseases Control, Gangdong Provincial Department of \\ Education, Key Laboratory of Functional Molecules from Marine Microorganisms, Gangdong Provincial Research Center for Severe \\ Infectious Disease Prevention and Control Technology, Zhongshan School of Medicine, Sun Yat-sen University, Guangzhou, China \\ ${ }^{2}$ Guangdong Provincial Center for Tuberculosis Control, Guangzhou, China \\ ${ }^{3}$ Bao'an Chronic Diseases Prevention and Cure Hospital, Shenzhen, China \\ ${ }^{4}$ Third Affiliated Hospital of Sun Yat-sen University, Guangzhou, China
}

Email: ${ }^{\dagger}$ szliu2005@sohu.com, ${ }^{\dagger}$ zhongqiu@vip.163.com, ${ }^{\dagger}$ laixm@mail.sysu.edu.cn

Received 21 March 2012; revised 20 April 2012; accepted 30 April 2012

\begin{abstract}
The aim of this study was to analyze the combination of three kinds of in-house IFN- $\gamma$ ELISPOT using peptide A53 and peptide mixtures (E6 + E7 and E6 + E7 + C14) with tuberculin skin test (TST) to detect latent TB infection (LTBI) in China. A total of $\mathbf{7 8 8}$ healthy people were recruited and analyzed by three kinds of IFN- $\gamma$ ELISPOT, 581 of them had TST results, of which 147 samples were also compared with the $T$ SPOT.TB test. The positive detection rates for $T$ SPOT.TB and three kinds of IFN- $\gamma$ ELISPOT with $\mathrm{A} 53$, E6 + E7 and E6 + E7 + C14 were $14.28 \%$ (21/147), 29.43\% (171/581), 23.24\% (135/581) and $28.40 \%(165 / 581)$, respectively. These results were significantly lower than the positive TST results, which were positive in $82.99 \%(122 / 147)$ and $75.73 \%(440 /$ 581), respectively. The positive detection rates of three kinds of IFN- $\gamma$ ELISPOT $(31.60 \%, 26.65 \%$ and $32.11 \%$ in 788 cases, respectively) could better reflect over $\mathbf{4 0 . 0 0 \%}$ of Mycobacterium tuberculosis (MTB) infection rate in China. Detection rates between contacts and non-contacts by three kinds of IFN- $\gamma$ ELIS-POT were not significantly different $(p>0.05)$. It can be seen that the three kinds of in-house IFN- $\gamma$ ELISPOT might be used as a complementary tool of TSPOT.TB for detecting LTBI in the healthy population of China.
\end{abstract}

Keywords: Latent TB Infection (LTBI); Detection; IFN- $\gamma$ ELISPOT; Healthy Population of China

*Conflict of interest: all of the authors listed in this manuscript have no conflicts of interest or financial interests to declare.

${ }^{\#}$ Contributed equally.

${ }^{\dagger}$ Corresponding authors.

\section{INTRODUCTION}

Tuberculosis (TB) is responsible for the greatest number of deaths attributable to a single infectious agent worldwide and most of this mortality is in developing countries [1]. For decades, the diagnosis of latent TB infection (LTBI) has relied on the tuberculin skin test (TST), which measures a delayed-type hypersensitivity response to a purified protein derivative (PPD) of more than 200 Mycobacterium tuberculosis (MTB) protein antigens [2, 3]. However, TST has some known limitations. For example, its specificity is limited due to PPD cross reactivity with the vaccination strain of $\mathrm{M}$. bovis Bacillus Calmette-Guérin (BCG), and several non-tuberculous mycobacteria (NTM) [3]. Therefore, individuals sensitized by previous exposures to NTM or vaccinated with $\mathrm{BCG}$ may respond immunologically to PPD.

The interferon gamma release assay (IGRAs) is an effective tool for enumerating the number of cells producing IFN- $\gamma$ in response to a whole series of antigens, including peptides, peptide pools, proteins and crude bacterial extracts. Tailor-made selection of antigens can be made, which for vaccine trials will include specific vaccine components as well as positive and negative controls. In addition, IGRAs has proven particularly sensitive in the detection of low-level responses when compared to other assays [4,5]. IGRAs are utilized in the diagnosis of LTBI [6,7]. However, their performance appears to vary between high burden, resource limited settings and low burden countries [8]. They may also have value in the evaluation of new tools against TB.

Recently, tests for in vitro diagnosis of LTBI based on the measurement of interferon-gamma (IFN- $\gamma$ ) produc- 
tion from peripheral blood mononuclear cells (PBMCs) and whole blood in response to specific MTB secreted antigens have been developed [9]. Studies have suggested that IGRAs using the two specific antigens of MTB-early secretory antigenic target 6 (ESAT-6) and culture filtrate protein 10 (CFP-10) were more specific than the TST for the diagnosis of LTBI [6]. It is reported that effective treatment for LTBI is associated with a decrease in the measured response to ESAT- 6 and CFP10 antigens $[10,11]$. In addition, Antigen $85 \mathrm{~B}$ is the most abundant protein exposed by MTB, as well as a potent immunoprotective antigen and a leading drug target. Ag85 induces strong T-cell proliferation and IFN- $\gamma$ secretion in most healthy individuals and BCG-vaccinated humans exposed to MTB.

In our previous study, we obtained ten peptides which originated from ESAT-6, CFP-10 or Ag85B which are specific to Chinese people in Guangzhou, China. These ten peptides including E6, E7 and C14 which had strong reaction to confirmed TB patients. The populations studied in most scientific research previously were confirmed TB patients, but few focused on healthy population, especially in China. And none of existing assays are widely used in China mainly because of the high cost of these kits. Here we used three kinds of in-house IFN- $\gamma$ ELISPOT established by our laboratory to monitor healthy population of china, at the same time, compared three kinds of in-house IFN- $\gamma$ ELISPOT with T-SPOT.TB, a commercial IFN- $\gamma$ ELISPOT-based test, and TST to evaluate the methodological characteristics for detecting LTBI in healthy population of China.

\section{MATERIALS AND METHODS}

\subsection{Study Population}

A total of 788 healthy people from Bao'an district of Shenzhen city in China were recruited to the study during from July to August 2010. Their ages ranged from 16 to 89 years (Mean \pm standard deviation was $46.74 \pm$ 14.90). Of the 788 participants, $10.15 \%$ (80/788) were household contacts, and had been in close contact with sputum smear or culture-positive TB patients in their families. $89.85 \%(708 / 788)$ participants were assigned to the non-contacts group, who seldom contacted with sputum smear or culture-positive TB patients in daily life. The participants were asked if they had received a BCG vaccine soon after birth and were examined by chest $\mathrm{x}$-ray and sputum smear or culture. The peripheral blood (PBL) samples from all the participants were monitored with three kinds of in-house IFN- $\gamma$ ELISPOT tests; and partial PBL samples were detected with T-SPOT.TB test at the same time. Immediately after the blood sample was drawn they underwent a TST. All adults who were enrolled agreed by written informed consent to partici- pate in the study. The study was approved by the Ethics Committee of Sun Yat-sen University.

\subsection{Tuberculin Skin Test (TST)}

TST was performed by intracutaneous injection of 5 TU/0.1 ml of tuberculin RT23 (Chengdu Institute of Biological Products, China) in the volar surface of the forearm. The TST was administered and read by staff from the Institute of Tuberculosis Prevention and Treatment of Guangdong Province and the Bao'an Chronic Diseases Prevention and Cure Hospital. Indurations were measured at $48-72 \mathrm{~h}$ by two independent readers [12]. Following American Thoracic Society and the Centers for Disease Control and Prevention guideline a diameter equal or greater than $5 \mathrm{~mm}$ was considered positive [13].

\subsection{Three Kinds of In-House IFN- $\gamma$ ELISPOT Assays}

In our previous work we obtained a mycobacteria-shared Ag85B peptide A53, two MTB-specific ESAT-6 peptides E6 (18-32aa, IQGNVTSIHSLLDEG, Chinese patent Application No. CN 20111130364.8) and E7 (2539aa, IHSLLDEGKQSLTKL, Chinese patent Publication No. CN 101446585A) [14], and an MTB-specific CFP-10 peptide C14, A53, E6 + E7 mixture and E6 + E7 $+\mathrm{C} 14$ mixture, with $10 \mu \mathrm{g} / \mathrm{ml}$ of each peptide, were used as antigen stimuli to perform three kinds of IFN- $\gamma$ ELISPOT assay respectively. Briefly, PBMCs were separated from the fresh PBL by Ficoll-Hypaque density gradient (Amersham Bioscience, Netherlands) centrifugation. Then $2.5 \times 10^{5}$ PBMCs mixed with the above antigens per well were plated onto a 96-well polyvinylidene fluoride (PVDF)-backed plate (MultiScreen-IP, Millipore, USA) which had been pre-coated with mouse anti-human IFN- $\gamma$ monoclonal antibody ( $5 \mu \mathrm{g} / \mathrm{ml}$, eBioscience, USA), and incubated at $37^{\circ} \mathrm{C}$ for $18 \mathrm{~h}$. Phorbol myristate acetate (PMA, $25 \mathrm{ng} / \mathrm{ml}$, Sigma, UK) and Ionomycin $(1 \mu \mathrm{g} / \mathrm{ml}$, Sigma, UK) mixed stimulus was used as positive control, as well as stimulus-free medium as negative control and cell-free medium as background control. After washing with $0.05 \%$ Tween-20 in phosphatebuffered saline (PBST), biotin-conjugated mouse poly-clonal anti-human IFN- $\gamma$ antibody $(0.5 \mu \mathrm{g} / \mathrm{ml}$, eBioscience, USA) was added and incubated for $2 \mathrm{~h}$ at room temperature. Wash again and alkaline phosphate-conjugated streptavidin $(2 \mu \mathrm{g} / \mathrm{ml}$, Thermo, USA) was added and incubated for $2-2.5 \mathrm{~h}$ at room temperature. After a washing step, the NBT/BCIP substrate buffer was added to visualization. At last, wash the plate thoroughly with distilled water to stop the detection reaction. Then the individual spots were counted using an automated image analysis system ELISPOT reader (Cellular Technology Ltd., USA). All readings were manually verified. SFP (spot forming cells (SFC) $/ 10^{6}$ 
PBMCs) $\geq 50$ than negative control was used as the standard indicating positivity in this study.

\subsection{T-SPOT.TB Assay}

The T-SPOT.TB (Oxford Immunotec, UK) assay was performed using whole PBL according to the manufacturer's instruction. Four wells with a membrane precoated with mouse anti-human IFN- $\gamma$ monoclonal antibody were used for each subject. The assay requires a total of $2.5 \times 10^{5}$ viable cells each well. Cells in each well were stimulated with medium alone as negative control, phytohemagglutinin (PHA) as positive control and different peptide panels with the MTB-specific antigens ESAT-6 (panel A) and CFP-10 (panel B). Finally, the individual spots were counted and manually verified as described above. Subjects were considered positive if there was a positive response to one or both antigen panels; the background number of spots in negative control wells was always less than five spots per well; the response of stimulated cultures was considered negative when the test well contained $<50$ spots; in general, a positive response was defined as $\geq 25 \mathrm{SFP}$ (SFC/ $10^{6}$ viable cells) on either panel A or panel B, or both.

\subsection{Data Management and Analysis}

Data analyses were performed using the statistical software SPSS version 16.0. Test results were considered statistically significant if the p-value was less than 0.05 . GraphPad Prism version 5.0 was used to construct the graphs and figures.

\section{RESULTS}

\subsection{Total Detection Results by Three Kinds of In-House IFN- $\gamma$ ELISPOT}

788 PBL samples from healthy individuals from Baoan District, Shenzhen city, who all were inoculated with BCG vaccine in juvenile, were detected by three kinds of in-house IFN- $\gamma$ ELISPOT, which was established by using peptide A53, and peptide mixtures E6 + E7 and E6 + E7 + C14 respectively. Detection results showed that SFP ranged from 150 to 1400 by three kinds of IFN- $\gamma$ ELISPOT, and no great differences in the distribution of SFP among them could be seen (Figure 1).

In addition, chest $\mathrm{x}$-ray examination and sputum smear or culture were negative in all 788 cases.

\subsection{The Detection Results Comparison of T-SPOT.TB or Three Kinds of In-House IFN- $\gamma$ ELISPOT and TST}

147 PBL samples in above 788 cases were detected with T-SPOT.TB assay. Moreover, TST results were obtained

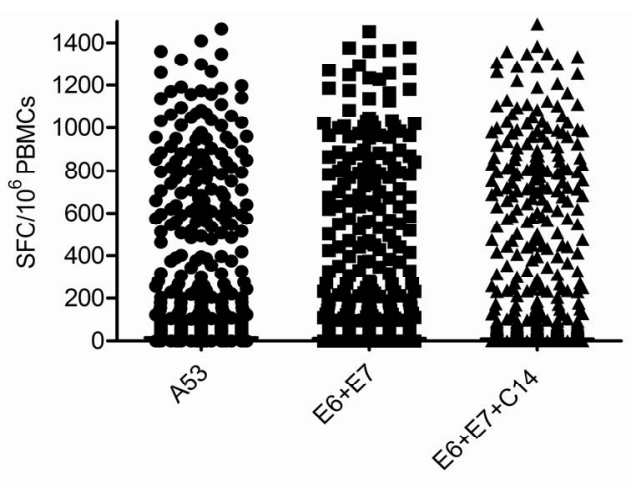

Figure 1. Comparison of SFP distributions among three kinds of in-house IFN- $\gamma$ ELISPOT. 788 PBL samples from healthy population were detected by three kinds of IFN $-\gamma$ ELISPOT established by using peptide A53, and peptide mixtures E6 + E7 and E6 $+\mathrm{E} 7+\mathrm{C} 14$ respectively. SFP (spot forming cells/ 106 PBMCs, SFC/106 PBMCs) ranged from 0 to 1400 by three kinds of IFN- $\gamma$-ELISPOT, and no great differences in the distributions of SFP among them could be seen.

in 581 including 147 cases with T-SPOT.TB assay out of 788 individuals by tracking. Comparison of results between T-SPOT.TB or IFN- $\gamma$ ELISPOT and TST are shown in Figures $\mathbf{2}$ to $\mathbf{4}$ and Tables 1 and 2.

As shown in Table 1, the positive detection rate by T-SPOT.TB assay was $14.29 \%(21 / 147)$, in contrast, and the results by three kinds of IFN- $\gamma$ ELISPOT (A53, E6 + E7 and E6 + E7 + C14) were 29.43\% (171/581), 23.24\% $(135 / 581)$ and $28.40 \%(165 / 581)$ respectively (Table 2$)$. Significantly lower positive detection rates by all the ELISPOT assays than by TST, which was positive in $82.99 \%(122 / 147)$ and $75.73 \%(440 / 581)$ respectively, could be observed. The positive and negative detections of three kinds of IFN- $\gamma$ ELISPOT compared with each TST detection groups were shown in Figures 2 and $\mathbf{3}$ and Table 2, the results suggested that there were little differences among three kinds of IFN- $\gamma$ ELISPOT in each TST detection groups whether positive or negative results of TST; in other words, there were similar positive detection levels by three kinds of IFN- $\gamma$ ELISPOT in each TST detection groups including negative group. Figure 4 and Table 1 provides details of positive and negative results in relation to T-SPOT.TB assay compared with each TST detection groups. The similar results could be seen as in comparison of three kinds of IFN- $\gamma$ ELISPOT assay and TST detection.

The descriptive analysis, a statistical analysis based respectively on SFP results and detection rates of three kinds of IFN- $\gamma$ ELISPOT and T-SPOT.TB in each and total TST detection groups, was shown in Table 3, and the detailed comparisons and similar conclusions as described above between three kinds of IFN- $\gamma$ ELISPOT or 


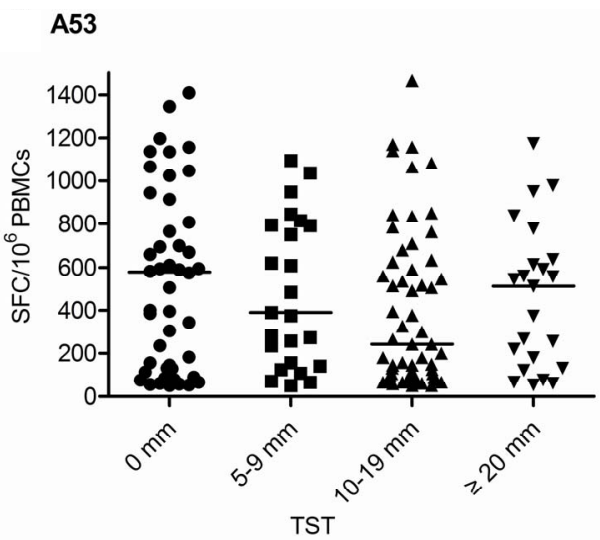

(a)

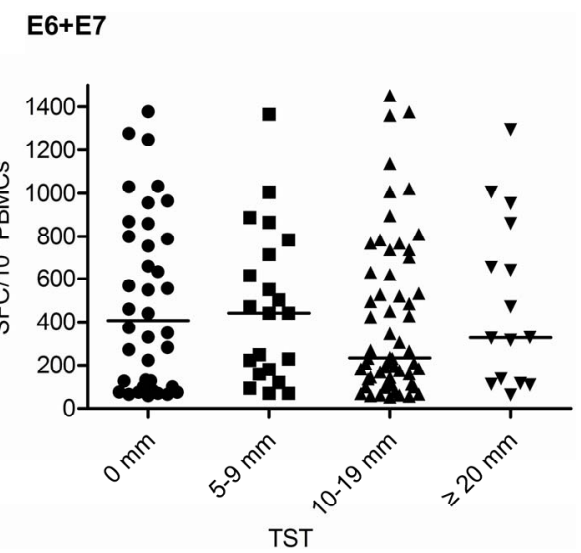

(b)

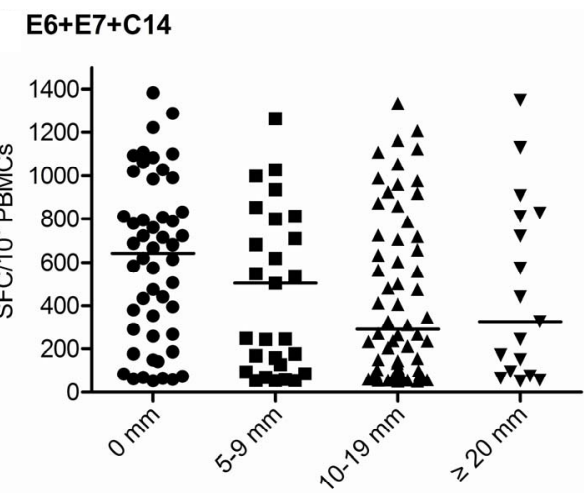

(c)

Figure 2. Comparison of positive SFP distributions by three kinds of in-house IFN- $\gamma$ ELISPOT in each tuberculin skin test (TST) group. 581 of 788 cases were detected by three kinds of IFN- $\gamma$ ELISPOT and TST at the same time. There were little differences with positive SFP distributions among each TST groups.

T-SPOT.TB and TST detection respectively were got.

Above all results suggested that ELISPOT assays including T-SPOT.TB and ours could reduce the false positive and false negative detection rates of TST.

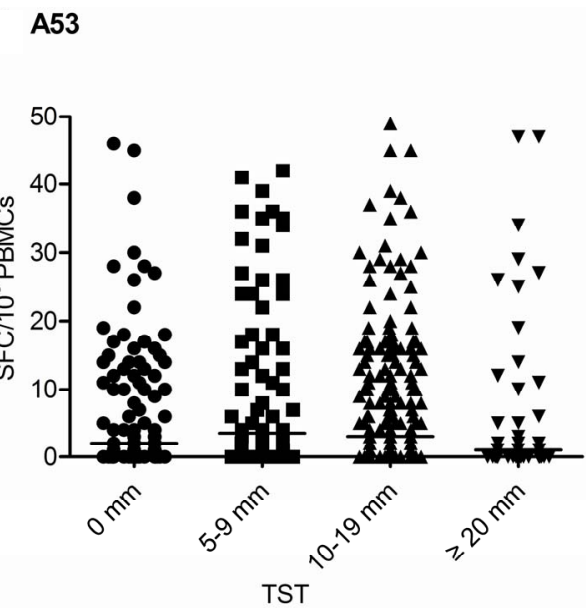

(a)

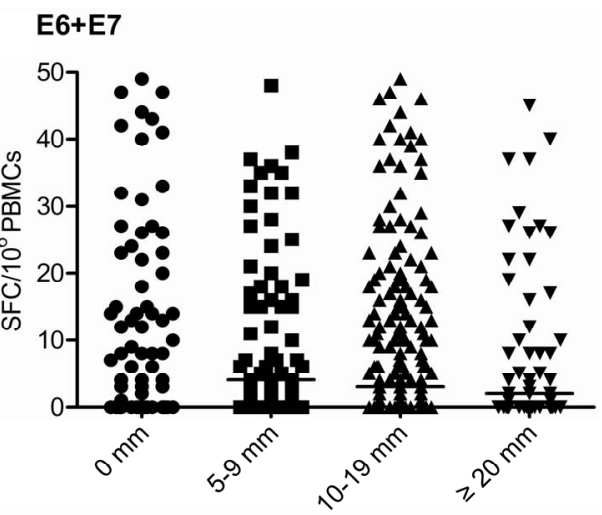

TST

(b)

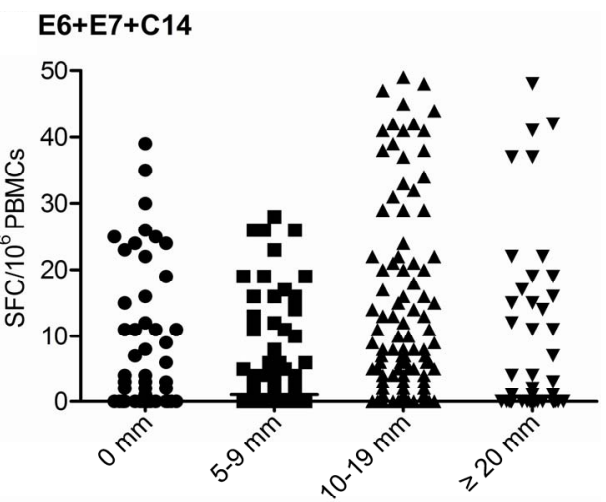

TST

(c)

Figure 3. Comparison of negative SFP distributions by three kinds of in-house IFN- $\gamma$ ELISPOT in each tuberculin skin test (TST) group. 581 of 788 cases were detected by three kinds of IFN- $\gamma$ ELISPOT and TST at the same time. There were little differences with negative SFP distributions by A53/ IFN- $\gamma$ ELISPOT and E6 + E7/IFN- $\gamma$ ELISPOT among each TST groups, while SFP was lower by $\mathrm{E} 6+\mathrm{E} 7+\mathrm{C} 14 / \mathrm{IFN}-\gamma$ ELISPOT in TST induration of 5 - $9 \mathrm{~mm}$ group than other TST groups. 


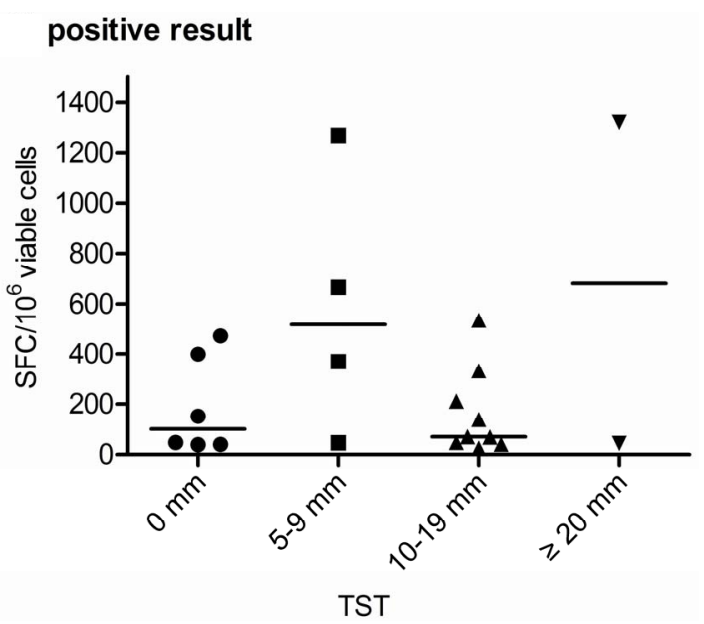

(a)

\section{negative result}

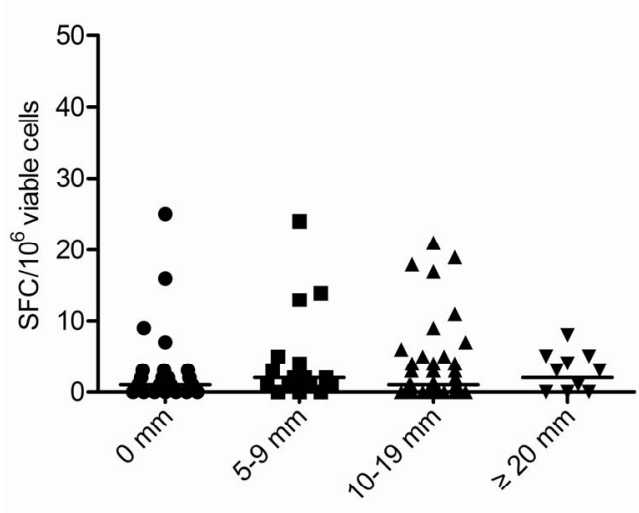

TST

(b)

Figure 4. Comparison of positive and negative SFP distributions by T-SPOT.TB in each tuberculin skin test (TST) group. 147 of 581 cases were detected by T-SPOT.TB and TST at the same time. There were little differences with positive and negative SFP distributions among each TST groups.

Table 1. The detection rates comparison of T-SPOT.TB and tuberculin skin test (TST).

\begin{tabular}{ccccccc}
\hline \multirow{2}{*}{ T-SPOT.TB $^{1}$} & & \multicolumn{5}{c}{ TST $^{2}$} \\
\cline { 3 - 7 } & & Negative $(0 \mathrm{~mm})$ & $+(5-9 \mathrm{~mm})$ & $++(10-19 \mathrm{~mm})$ & $+++(\geq 20 \mathrm{~mm})$ & Total \\
\hline \multirow{2}{*}{ Total of panel A and panel B } & Positive & $6(4.08 \%)$ & $4(2.72 \%)$ & $9(6.12 \%)$ & $2(1.36 \%)$ & $21(14.29 \%)$ \\
& Negative & $19(12.93 \%)$ & $52(35.38 \%)$ & $39(26.53 \%)$ & $16(10.88 \%)$ & $126(85.71 \%)$ \\
& Total & $25(17.01 \%)$ & $56(38.10 \%)$ & $48(32.65 \%)$ & $18(12.24 \%)$ & 147 \\
\hline
\end{tabular}

${ }^{1}$ The percentages of T-SPOT.TB and TST detections were all calculated with total 147 cases; ${ }^{2}$ No individual was found with a TST induration of $1-4 \mathrm{~mm}$. There was significant difference between T-SPOT.TB and TST detections $(\mathrm{p}<0.05)$.

Table 2. The detection rates comparison of three kinds of in-house IFN- $\gamma$ ELISPOT and tuberculin skin test (TST).

\begin{tabular}{|c|c|c|c|c|c|c|}
\hline \multirow{2}{*}{\multicolumn{2}{|c|}{ 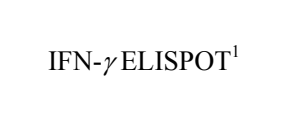 }} & \multicolumn{5}{|c|}{$\mathrm{TST}^{2}$} \\
\hline & & Negative $(0 \mathrm{~mm})$ & $+(5-9 \mathrm{~mm})$ & $++(10-19 \mathrm{~mm})$ & $+++(\geq 20 \mathrm{~mm})$ & Total \\
\hline \multirow{3}{*}{ A53 } & Positive & $63(10.84 \%)$ & $24(4.13 \%)$ & $61(10.50 \%)$ & $23(3.96 \%)$ & $171(29.43 \%)$ \\
\hline & Negative & $78(13.43 \%)$ & $77(13.25 \%)$ & $201(34.60 \%)$ & $54(9.29 \%)$ & $410(70.57 \%)$ \\
\hline & Total & $141(24.27 \%)$ & $101(17.38 \%)$ & $262(45.10 \%)$ & 77 (13.25\%) & 581 \\
\hline \multirow{3}{*}{$\mathrm{E} 6+\mathrm{E} 7$} & Positive & $33(5.68 \%)$ & $21(3.61 \%)$ & $63(10.85 \%)$ & $18(3.10 \%)$ & $135(23.24 \%)$ \\
\hline & Negative & $108(18.59 \%)$ & $80(13.77 \%)$ & $199(34.25 \%)$ & $59(10.15 \%)$ & $446(76.76 \%)$ \\
\hline & Total & $141(24.27 \%)$ & $101(17.38 \%)$ & $262(45.10 \%)$ & 77 (13.25\%) & 581 \\
\hline \multirow{3}{*}{$\begin{array}{c}\mathrm{E} 6+\mathrm{E} 7 \\
+\mathrm{C} 14\end{array}$} & Positive & $47(8.09 \%)$ & $33(5.68 \%)$ & $65(11.19 \%)$ & $20(3.44 \%)$ & $165(28.40 \%)$ \\
\hline & Negative & $94(16.18 \%)$ & $68(11.70 \%)$ & $197(33.91 \%)$ & $57(9.81 \%)$ & $416(71.60 \%)$ \\
\hline & Total & $141(24.27 \%)$ & $101(17.38 \%)$ & $262(45.10 \%)$ & $77(13.25 \%)$ & 581 \\
\hline
\end{tabular}

${ }^{1}$ The percentages of three kinds of IFN- $\gamma$ ELISPOT and TST detections were all calculated with total 581 cases; ${ }^{2}$ No individual was found with a TST induration of $1-4 \mathrm{~mm}$. There was significant difference between three kinds of IFN- $\gamma$ ELISPOT and TST detections respectively ( $\mathrm{p}<0.05$ ). 
Table 3. The SFP results of three kinds of in-house IFN- $\gamma$ ELISPOT and T-SPOT.TB in each and total tuberculin skin test (TST) detection groups.

\begin{tabular}{|c|c|c|c|c|c|c|c|c|c|c|c|c|c|c|c|c|c|c|c|c|c|}
\hline \multirow{3}{*}{ IFN- $\gamma$ ELISPOT or } & \multirow{3}{*}{ T-SPOT.TB } & \multicolumn{20}{|c|}{$\mathrm{TST}^{1}$} \\
\hline & & \multicolumn{4}{|c|}{ Negative $(0 \mathrm{~mm})$} & \multicolumn{4}{|c|}{$+(5-9 \mathrm{~mm})$} & \multicolumn{4}{|c|}{$++(10-19 \mathrm{~mm})$} & \multicolumn{4}{|c|}{$+++(\geq 20 \mathrm{~mm})$} & \multicolumn{4}{|c|}{ Total } \\
\hline & & $\mathrm{N}^{2}$ & $\mathrm{P} 25^{3}$ & $\mathrm{P} 50^{4}$ & $\mathrm{P} 75^{5}$ & $\mathrm{~N}$ & $\mathrm{P} 25$ & P50 & P75 & $\mathrm{N}$ & $\mathrm{P} 25$ & P50 & P75 & $\mathrm{N}$ & P25 & P50 & P75 & $\mathrm{N}$ & P25 & P50 & P75 \\
\hline \multirow{2}{*}{ A53 } & Positive & 63 & 130 & 579 & 938 & 24 & 149 & 391 & 805 & 61 & 98 & 243 & 630 & 23 & 131 & 513 & 637 & 171 & 114 & 387 & 765 \\
\hline & Negative & 78 & 0 & 2 & 13 & 77 & 0 & 4 & 18 & 201 & 0 & 3 & 13 & 54 & 0 & 1 & 6 & 410 & 0 & 2 & 13 \\
\hline \multirow{2}{*}{$\mathrm{E} 6+\mathrm{E} 7$} & Positive & 33 & 100 & 407 & 816 & 21 & 170 & 442 & 750 & 63 & 131 & 234 & 650 & 18 & 115 & 328 & 861 & 135 & 127 & 329 & 738 \\
\hline & Negative & 108 & 0 & 0 & 14 & 80 & 0 & 4 & 17 & 199 & 0 & 3 & 14 & 59 & 0 & 2 & 12 & 446 & 0 & 2 & 14 \\
\hline \multirow{2}{*}{$\mathrm{E} 6+\mathrm{E} 7+\mathrm{C} 14$} & Positive & 47 & 265 & 644 & 871 & 33 & 113 & 504 & 834 & 65 & 90 & 291 & 773 & 20 & 86 & 325 & 820 & 165 & 131 & 459 & 813 \\
\hline & Negative & 94 & 0 & 0 & 4 & 68 & 0 & 1 & 9 & 197 & 0 & 0 & 8 & 57 & 0 & 0 & 13 & 416 & 0 & 0 & 8 \\
\hline \multirow{2}{*}{ T-SPOT.TB } & Positive & 6 & 48 & 152 & 399 & 4 & 128 & 518 & 1117 & 9 & 69 & 139 & 332 & 2 & 44 & 682 & 1319 & 21 & 53 & 182 & 501 \\
\hline & Negative & 19 & 0 & 1 & 3 & 52 & 1 & 2 & 5 & 39 & 0 & 1 & 4 & 16 & 0 & 22 & 5 & 126 & 0 & 1 & 3 \\
\hline
\end{tabular}

${ }^{1}$ No individual was found with a TST induration of $1-4 \mathrm{~mm} ;{ }^{2}$ Number detected; ${ }^{3}$ Lower quartile of SFP (spot forming cells $/ 10^{6}$ PBMCs or viable cells) detected by three kinds of IFN- $\gamma$ ELISPOT and T-SPOT.TB; ${ }^{4}$ Median of SFP detected by IFN- $\gamma$ ELISPOT and T-SPOT.TB; ${ }^{5}$ Upper quartile of SFP detected by IFN- $\gamma$ ELISPOT and T-SPOT.TB. Significant SFP differences were found between three kinds of IFN- $\gamma$ ELISPOT and T-SPOT.TB in total TST detection group respectively $(\mathrm{p}<0.05)$, but no significant differences among three kinds of IFN $-\gamma$ ELISPOT and T-SPOT.TB respectively, as well as among each TST detection groups $(\mathrm{p}>0.05)$.

\subsection{The Detection Results Comparison of In-House IFN- $\gamma$ ELISPOT and T-SPOT.TB Assays}

The detection results of 147 cases are summarized in Table 4. Positive T-SPOT.TB detection rate was observed in $14.29 \%$ (21/147), in comparison with $29.93 \%$ (44/147) by two kinds of IFN- $\gamma$ ELISPOT in combination of E6 + E7 with E6 + E7 + C14; and higher positive detection rate by latter than former $(\mathrm{p}<0.05)$.

In addition, as shown in Table 3, the median (P50) of the positive SFP of A53 panel, E6 + E7 panel and E6 + E7 + C14 panel in IFN- $\gamma$-ELISPOT in 581 cases, and total panel A and panel B in T-SPOT.TB in 147 cases were 387, 329, 459 and 182, respectively. Significant SFP differences were found between three kinds of IFN- $\gamma$ ELISPOT and T-SPOT.TB in total TST detection group respectively $(\mathrm{p}<0.05)$, but no significant differences among three kinds of IFN- $\gamma$ ELISPOT, as well as among each TST detection groups $(\mathrm{p}>0.05)$.

Above results suggested that three kinds of in-house IFN- $\gamma$ ELISPOT have similar sensitivity as T-SPOT.TB at least.

\subsection{The Detection Results Comparisons of Three Kinds of In-House IFN- $\gamma$ ELISPOT Assays}

$\mathrm{A} 53, \mathrm{E} 6+\mathrm{E} 7$ and $\mathrm{E} 6+\mathrm{E} 7+\mathrm{C} 14$ were respectively used to accomplish IFN- $\gamma$ ELISPOT detecting in $788 \mathrm{PBL}$ samples; Tables $\mathbf{5}$ and $\mathbf{6}$ showed that positive detection rates were $31.60 \%$ (249/788), 26.65\% (210/788), 32.11\% $(253 / 788)$ and $38.45 \%(303 / 788)$ in A53, E6 + E7, E6 + $\mathrm{E} 7+\mathrm{C} 14$ and combination $\mathrm{E} 6+\mathrm{E} 7$ with $\mathrm{E} 6+\mathrm{E} 7+\mathrm{C} 14$ respectively. Except between A53 and E6 + E7 + C14 detecting $(\mathrm{p}>0.05)$, it could be seen that higher positive detection rate by $\mathrm{E} 6+\mathrm{E} 7+\mathrm{C} 14$ assay was obtained than by E6 + E7 assay $(\mathrm{p}<0.05)$, as well as by A53 assay than by E6 + E7 assay $(p<0.05)$ and by combination E6 + E7 with E6 + E7 + C14 assays than A53 assay (p < $0.05)$.

Since peptide A53 is mycobacteria-shared, the finding of positive A53 detections but negative E6 + E7 and E6 $+\mathrm{E} 7+\mathrm{C} 14$ detections might indicate that these participants were likely to be NTM-infected or BCG-vaccinated individuals. In the future practical application, combination E6 + E7 with E6 + E7 + C14 assays could be used to improve detection rates of MTB infections, and adding A53 assay to discriminate MTB infections from NTM infections or BCG vaccinations.

\subsection{The Detection Results Comparisons of 80 TB Contacts and 501 Non-Contacts with Three Kinds of In-House IFN- $\gamma$ ELISPOT and TST}

The PBL samples of 80 TB contacts from 581 cases were also examined with three kinds of IFN- $\gamma$ ELISPOT assays (A53, E6 + E7 and E6 + E7 + C14), the positive detection rates appeared $30.00 \%(24 / 80), 30.00 \%(24 / 80)$ and $28.75 \%(23 / 80)$ respectively, in comparison with $29.34 \%$ (147/501), 22.56\% (111/501) and 28.34\% (142/ $501)$ in 501 non-contacts' samples respectively. No significantly different detection rates between contacts and non-contacts by three kinds of IFN- $\gamma$ ELISPOT respectively were found $(\mathrm{p}>0.05$, Table 7$)$. Perhaps some contacts of negative IFN- $\gamma$ ELISPOT detections were not 
Table 4. The detection rates comparison of in-house IFN- $\gamma$ ELISPOT in combination of E6 + E7 with E6 + E7 + C14 and TSPOT.TB.

\begin{tabular}{cccc}
\hline \multirow{2}{*}{$\begin{array}{c}\text { IFN- } \gamma \text { ELISPOT } \\
(\text { E6 }+ \text { E7 } \text { and E6 }+ \text { E7 }+ \text { C14 })^{1}\end{array}$} & T-SPOT.TB (panel A and panel B) ${ }^{1}$ & Total \\
\cline { 2 - 4 } & Positive & Negative & $44(29.93 \%)$ \\
Positive & $6(4.08 \%)$ & $38(25.85 \%)$ & $103(70.07 \%)$ \\
Negative & $15(10.21 \%)$ & $88(59.86 \%)$ & 147 \\
Total & $21(14.29 \%)$ & $126(85.71 \%)$ & \\
\hline
\end{tabular}

${ }^{1}$ The percentages of IFN- $\gamma$ ELISPOT and T-SPOT.TB detections were all calculated with total 147 cases. There was significant difference between both tests detections $(\mathrm{p}<0.05)$.

Table 5. The detection rates comparison of E6 + E7/IFN- $\gamma$ ELISPOT and E6 + E7 + C14/IFN- $\gamma$ ELISPOT.

\begin{tabular}{cccc}
\hline \multirow{2}{*}{ E6 + E7/IFN- $\gamma$ ELISPOT $^{1}$} & & ${\text { E6 }+ \text { E7 }+ \text { C14/IFN- } \gamma \text { ELISPOT }^{1}}$ \\
\cline { 2 - 4 } & Positive & Negative & Total \\
\hline Positive & $160(20.31 \%)$ & $50(6.34 \%)$ & $210(26.65 \%)$ \\
Negative & $93(11.80 \%)$ & $485(61.55 \%)$ & $578(73.35 \%)$ \\
Total & $253(32.11 \%)$ & $535(67.89 \%)$ & 788 \\
\hline
\end{tabular}

${ }^{1}$ The percentages of two kinds of IFN- $\gamma$ ELISPOT detections were all calculated with total 788 cases. There was significant difference between both tests detections $(\mathrm{p}<0.05)$.

Table 6. The detection rates comparison of three kinds of in-house IFN- $\gamma$ ELISPOT assays.

\begin{tabular}{|c|c|c|c|c|}
\hline \multirow{2}{*}{\multicolumn{2}{|c|}{ 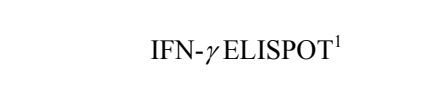 }} & \multicolumn{3}{|c|}{ A53/IFN- $\gamma$ ELISPOT $^{1}$} \\
\hline & & Positive & Negative & Total \\
\hline \multirow{3}{*}{$\mathrm{E} 6+\mathrm{E} 7$} & Positive & $153(19.42 \%)$ & $57(7.23 \%)$ & $210(26.65 \%)$ \\
\hline & Negative & $96(12.18 \%)$ & $482(61.17 \%)$ & $578(73.35 \%)$ \\
\hline & Total & $249(31.60 \%)$ & $539(68.40 \%)$ & 788 \\
\hline \multirow{3}{*}{$\begin{array}{c}\text { E6 + E7 } \\
+ \text { C14 }\end{array}$} & Positive & 157 (19.92\%) & $96(12.18 \%)$ & $253(32.11 \%)$ \\
\hline & Negative & $92(11.68 \%)$ & $443(56.22 \%)$ & $535(67.89 \%)$ \\
\hline & Total & $249(31.60 \%)$ & $539(68.40 \%)$ & 788 \\
\hline \multirow{3}{*}{$\begin{array}{c}\mathrm{E} 6+\mathrm{E} 7 \text { and } \mathrm{E} 6+ \\
\mathrm{E} 7+\mathrm{C} 14\end{array}$} & Positive & $185(23.48 \%)$ & $118(14.97 \%)$ & $303(38.45 \%)$ \\
\hline & Negative & $64(8.12 \%)$ & $421(53.43 \%)$ & $485(61.55 \%)$ \\
\hline & Total & 249 (31.60\%) & $539(68.40 \%)$ & 788 \\
\hline
\end{tabular}

${ }^{1}$ The percentages of IFN- $\gamma$ ELISPOT in combination of E6 + E7 with E6 + E7 + C14 and three kinds of IFN- $\gamma$ ELISPOT detections were all calculated with total 788 cases. No significant difference was found between E6 + E7 + C14/IFN- $\gamma$ ELISPOT and A53/IFN- $\gamma$ ELISPOT detections ( $p>0.05$ ). There was significant difference between E6 + E7/IFN $-\gamma$ ELISPOT and A53/IFN- $\gamma$ ELISPOT detections $(\mathrm{p}<0.05)$. There was significant difference between combination of $\mathrm{E} 6+\mathrm{E} 7$ with E6 + E7 + C14 in IFN $-\gamma$ ELISPOT and A53/IFN $-\gamma$ ELISPOT detections $(\mathrm{p}<0.05)$.

Table 7. The detection rates comparison of $80 \mathrm{~TB}$ contacts and 501 non-contacts by three kinds of in-house IFN- $\gamma$ ELISPOT.

\begin{tabular}{ccccccc}
\hline & \multicolumn{4}{c}{ Cases groups } \\
\cline { 2 - 7 }${\text { IFN- } \gamma \text { ELISPOT }^{1}}$ & \multicolumn{2}{c}{ Contacts $(\mathrm{N}=80)$} & \multicolumn{2}{c}{ Non-contacts $(\mathrm{N}=501)$} & \multicolumn{2}{c}{ Total (N=581) } \\
\cline { 2 - 7 } & Positive & Negative & Positive & Negative & Positive & Negative \\
\hline A53 & $24(30.00 \%)$ & $56(70.00 \%)$ & $147(29.34 \%)$ & $354(70.66 \%)$ & $249(31.60 \%)$ & $539(68.40 \%)$ \\
E6 + E7 & $24(30.00 \%)$ & $56(70.00 \%)$ & $111(22.56 \%)$ & $390(77.84 \%)$ & $210(26.65 \%)$ & $578(73.35 \%)$ \\
E6 + E7 + C14 & $23(28.75 \%)$ & $57(71.25 \%)$ & $142(28.34 \%)$ & $359(71.66 \%)$ & $253(32.11 \%)$ & $535(67.89 \%)$ \\
\hline
\end{tabular}

${ }^{1}$ The percentages of IFN- $\gamma$ ELISPOT detections were calculated with each cases group. No significant differences in detection rate by three kinds of IFN $-\gamma$ ELISPOT were found between contacts and non-contacts $(p>0.05)$. 
infected with mycobacteria or still had no immune responses during initial infection period. Therefore, a further tracking detection is needed.

As showed in Table 8 and previously described, the positive detection rates of three kinds of IFN- $\gamma$ ELISPOT were also significantly lower than those $(82.50 \%, 66 / 80)$ of TST ( $<<0.05$ ); on the other hand, high positive detection rates of three kinds of IFN- $\gamma$ ELISPOT in negative TST group were also found.

\section{DISCUSSION}

In this TB investigation we performed TST, in-house IFN- $\gamma$ ELISPOT and T-SPOT.TB analyses among a large group of healthy sampling population of Baoan District in Shenzhen City, China. Meanwhile, in our previous work we found that the positive detection rates of E6 + $\mathrm{E} 7, \mathrm{E} 6+\mathrm{E} 7+\mathrm{C} 14$, combination E6 + E7 with E6 + E7 $+\mathrm{C} 14$, and total of panel A and panel B of T-SPOT.TB were $88.37 \%$ (76/86), 94.19\% (81/86), 96.51\% (83/86) and $98.84 \%(85 / 86)$ respectively in 86 confirmed pulmonary TB cases; and the concurrently positive detection rates for our in-house IFN- $\gamma$ ELISPOT and T-SPOT.TB reached to $95.35 \%(82 / 86)$. Integrating above data with this study results, our finding highlights that: 1 ) The results for three kinds of in-house IFN- $\gamma$ ELISPOT (A53, $\mathrm{E} 6+\mathrm{E} 7$ and $\mathrm{E} 6+\mathrm{E} 7+\mathrm{C} 14)$ in comparison with TST results reflected that both sensitivity and specificity of three kinds of IFN- $\gamma$ ELISPOT was significantly higher than TST. 2) Three kinds of IFN- $\gamma$ ELISPOT were as sensitive as T-SPOT.TB test at least. 3) The combination of three kinds of IFN- $\gamma$ ELISPOT and TST may allow for a significantly better discrimination of diagnosis of LTBI than IGRA alone.
T cell based IFN $-\gamma$ assays that incorporate stimulatory antigens that are not found in BCG or many environmental mycobacteria, have been shown to have promise in the diagnosis of MTB infection after recent exposure [15-17]. IFN- $\gamma$ assays seem to be a promising alternative to the TST for the diagnosis of LTB [9]. In this respect, our results suggested that the positive detection rate for both three kinds of in-house IFN- $\gamma$ ELISPOT and TSPOT.TB were significantly lower than the positive TST results. And the results of TST detection group (including the negative group) had shown a certain positive detection rate of T-SPOT.TB and three kinds of IFN- $\gamma$ ELISPOT, suggesting that in-house IFN- $\gamma$ ELISPOT, like T-SPOT.TB, could reduce the false positive and false negative rate of TST. The three kinds of IFN- $\gamma$ ELISPOT, especially E6 + E7/IFN- $\gamma$ ELISPOT and E6 + E7 + C14/IFN- $\gamma$ ELISPOT, have potential advantages, beyond greater specificity and sensitivity.

The positive detection rates of A53, E6 + E7, E6 + E7 $+\mathrm{C} 14$ and combination E6 + E7 with E6 + E7 + C14 were $31.60 \%, 32.11 \%, 26.65 \%$ and $38.45 \%$ respectively in 788 cases. Except between A53 and E6 + E7 + C14 detecting $(\mathrm{p}>0.05)$, it could be seen that higher positive detection rate by $\mathrm{E} 6+\mathrm{E} 7+\mathrm{C} 14$ assay was obtained than by E6 + E7 assay $(\mathrm{p}<0.05)$, as well as by A53 assay than by E6 + E7 assay $(p<0.05)$ and by combination E6 $+\mathrm{E} 7$ with $\mathrm{E} 6+\mathrm{E} 7+\mathrm{C} 14$ assays than A53 assay $(\mathrm{p}<$ 0.05). The difference between E6 + E7 and E6 + E7 + C14 may be due to the interference and additive effect, which was caused by the mixture of peptides, derived from the proteins that exist only in the MTB complex group. In practice the two kinds of peptides can be added together to increase the positive detection rates, some of

Table 8. The detection rates comparison of three kinds of in-house IFN- $\gamma$ ELISPOT and tuberculin skin test (TST) in 80 TB contacts.

\begin{tabular}{|c|c|c|c|c|}
\hline \multirow{2}{*}{\multicolumn{2}{|c|}{ IFN- $\gamma$ ELISPOT $^{1}$}} & \multicolumn{3}{|c|}{$\mathrm{TST}^{1}$} \\
\hline & & Positive & Negative & Total \\
\hline \multirow{3}{*}{ A53 } & Positive & $19(23.75 \%)$ & $5(6.25 \%)$ & $24(30.00 \%)$ \\
\hline & Negative & $47(58.75 \%)$ & $9(11.25 \%)$ & $56(70.00 \%)$ \\
\hline & Total & $66(82.50 \%)$ & $14(17.50 \%)$ & 80 \\
\hline \multirow{3}{*}{$\mathrm{E} 6+\mathrm{E} 7$} & Positive & $17(21.25 \%)$ & $7(8.75 \%)$ & $24(30.00 \%)$ \\
\hline & Negative & $49(61.25 \%)$ & $7(8.75 \%)$ & $56(70.00 \%)$ \\
\hline & Total & $66(82.50 \%)$ & $14(17.50 \%)$ & 80 \\
\hline \multirow{3}{*}{$\mathrm{E} 6+\mathrm{E} 7+\mathrm{C} 14$} & Positive & $16(20.00 \%)$ & $7(8.75 \%)$ & $23(28.75 \%)$ \\
\hline & Negative & $50(62.50 \%)$ & $7(8.75 \%)$ & $57(71.25 \%)$ \\
\hline & Total & $66(82.50 \%)$ & $14(17.50 \%)$ & 80 \\
\hline
\end{tabular}

\footnotetext{
${ }^{1}$ The percentages of three kinds of IFN- $\gamma$ ELISPOT and TST detections were all calculated with total 80 cases. There was significant difference between three
} kinds of IFN $-\gamma$ ELISPOT and TST detections respectively $(\mathrm{p}<0.05)$. 
the positive individuals in these results may be LTBI. Since A53 is a peptide shared by mycobacteria, in theory, any mycobacteria including MTB and NTM-infected and BCG-vaccinated individuals could show positive, but may be due to a single peptide antigen stimulation effects and antigenic characteristics of the peptide itself, or BCG vaccination early at birth, resulting in some positive or BCG immune response disappeared individuals were detected as negative ones. In addition, the $14.29 \%$ positive detection rate in T-SPOT.TB results was significantly lower than the positive detection rate $(29.93 \%)$ for the combination of two kinds of IFN $-\gamma$ ELISPOT results in the same 147 cases, and the positive detection rates for three kinds of IFN- $\gamma$ ELISPOT results (A53, E6 + E7 and $\mathrm{E} 6+\mathrm{E} 7+\mathrm{C} 14)$ were $29.43 \%, 23.24 \%$ and $28.40 \%$, respectively in 581 cases. The positive detection rates of IFN- $\gamma$ ELISPOT could better reflect over $40.00 \%$ of MTB infection rate in China. Moreover, 182 of median of the positive SFP in total panel A and panel B of T-SPOT.TB was also significantly less than those (387, 329 and 459 respectively) of three kinds of IFN- $\gamma$ ELISPOT. The results of discrimination may be related to differences in population of different HLA alleles and other relevant factors, the combination of E6 + E7 and $\mathrm{E} 6+\mathrm{E} 7+\mathrm{C} 14$ may be more suitable for Chinese to use. In the future practical application, combination E6 + E7 with E6 + E7 + C14 assays could be used to improve detection rates of MTB infections, and adding A53 assay to discriminate MTB infections from NTM infections or BCG vaccinations.

Household contacts of TB cases have a relatively high prevalence of TB disease when screened [18] and a higher incidence rate of TB disease than the general population in the first years after exposure, the rate varying across different locations and populations [19-22]. Our findings of the positive detection rate for three kinds of in-house IFN- $\gamma$ ELISPOT and TST in 80 TB contacts were in agreement with our data previously described in 581 cases, and again proved that both sensitivity and specificity of three kinds of IFN- $\gamma$ ELISPOT was higher than TST from the above. TB case contact studies are being engaged increasingly as platforms for studying TB infection and development and have potential in relation to the assessment of new diagnostic tests and interventions, including vaccines [7]. In our study, No significant differences in detection rate by three kinds of IFN- $\gamma$ ELISPOT were found between 80 contacts and 501 non-contacts respectively $(\mathrm{p}>0.05)$. Perhaps some contacts of negative IFN- $\gamma$ ELISPOT detections were not infected with mycobacteria or still had no immune responses during initial infection period. Therefore, a further long-term (e.g., 2 - 3 years) tracking detection is needed.

The diagnosis and management of LTBI has been im- proved by MTB-specific IGRAs in addition to the TST over the last decade [23]. Since previous studies have reported that T-SPOT.TB was a better marker for LTBI, and more related than TST to the well known risk factors (e.g. immunosuppression) for TB infection [24,25], TSPOT.TB is a useful tool for detecting of LTBI. However, because of the relatively high cost of the $\mathrm{T}$ SPOT.TB assay, it is probably a difficult task to perform prophylactic diagnosis of LTBI in reality for some low income families or individuals in developing countries. Our results indicated that the three kinds of in-house IFN- $\gamma$ ELISPOT could be used as a complement tool of T-SPOT.TB for detecting LTBI in healthy population of China while considering their relatively low costs.

\section{ACKNOWLEDGEMENTS}

This work was supported by the National Natural Sciences Foundation of China (30430660, to XL), the Serious Infectious Diseases Special Foundation of China (2008ZX10003-012, 2009ZX10003-018, and 2012ZX10004903-004-002, to XL). The funders had no role in the study design, data collection and analysis, decision to publish, or preparation of the manuscript. We greatly thank Dr. Yanbo Gao and Dr. Liang Chen at the Institute of Tuberculosis Prevention and Treatment of Guangdong Province and Dr. Lei Zhang at the Baoan Chronic Diseases Prevention and Cure Hospital for the collection of the information and PBL of healthy individuals, and all the participants for their involvement in this study.

\section{REFERENCES}

[1] World Health Organization (2007) WHO fact sheet. http://www.who.int/mediacentre/factsheets /fs104/en/

[2] Jasmer, R.M., Nahid, P. and Hopewell, P.C. (2002) Clinical practice. Latent tuberculosis infection. The New England Journal of Medicine, 347, 1860-1866. doi:10.1056/NEJMcp021045

[3] Huebner, R.E., Schein, M.F. and Bass, J.B. Jr. (1993) The tuberculin skin test. Clinical Infectious Diseases, 17, 968975. doi:10.1093/clinids/17.6.968

[4] Karlsson, A.C., Martin, J.N., Younger, S.R., Bredt, B.M., Epling, L., Ronquillo, R., Varma, A., Deeks, S.G., Mc Cune, J.M., Nixon, D.F. and Sinclair, E. (2003) Comparison of the ELISPOT and cytokine flow cytometry assays for the enumeration of antigen-specific $\mathrm{T}$ cells. Journal of Immunological Methods, 283, 141-153. doi:10.1016/j.jim.2003.09.001

[5] Tassignon, J., Burny, W., Dahmani, S., Zhou, L., Stordeur, P., Byl, B. and De Groote, D. (2005) Monitoring of cellular responses after vaccination against tetanus toxoid: Comparison of the measurement of IFN-gamma production by ELISA, ELISPOT, flow cytometry and real-time PCR. Journal of Immunological Methods, 305, 188-198. doi:10.1016/j.jim.2005.07.014

[6] Menzies, D., Pai, M. and Comstock, G. (2007) Metaanalysis: New tests for the diagnosis of latent tuberculosis 
infection: Areas of uncertainty and recommendations for research. Annals of Internal Medicine, 146, 340-354.

[7] Hill, P.C., Jackson-Sillah, D.J., Fox, A., Brookes, R.H., de Jong, B.C., Lugos, M.D., Adetifa, I.M., Donkor, S.A., Aiken, A.M., Howie, S.R., Corrah, T., McAdam, K.P. and Adegbola, R.A. (2008) Incidence of tuberculosis and the predictive value of ELISPOT and Mantoux tests in Gambian case contacts. PloS One, 3, e1379. doi:10.1371/journal.pone.0001379

[8] Dheda, K., Smit, R.Z., Badri, M. and Pai, M. (2009) Tcell interferon-gamma release assays for the rapid immunodiagnosis of tuberculosis: Clinical utility in high burden vs low-burden settings. Current Opinion in Pulmonary Medicine, 15, 188-200. doi:10.1097/MCP.0b013e32832a0adc

[9] Casas, I., Latorre, I., Esteve, M., Ruiz-Manzano, J., Rodriguez, D., Prat, C., García-Olivé, I., Lacoma, A., Ausina, V. and Domínguez, J. (2009) Evaluation of interferon-gamma release assays in the diagnosis of recent tuberculosis infection in health care workers. PloS One, 4, e6686. doi:10.1371/journal.pone.0006686

[10] Wilkinson, K.A., Kon, O.M., Newton, S.M., Meintjes, G., Davidson, R.N., Pasvol, G. and Wilkinson, R.J. (2006) Effect of treatment of latent tuberculosis infection on the $\mathrm{T}$ cell response to Mycobacterium tuberculosis antigens. Journal of Infectious Diseases, 193, 354-359. doi:10.1086/499311

[11] Chee, C.B., KhinMar, K.W., Gan, S.H., Barkham, T.M., Pushparani, M. and Wang, Y.T. (2007) Latent tuberculosis infection treatment and T-cell responses to Mycobacterium tuberculosis-specific antigens. American Journal of Respiratory and Critical Care Medicine, 175, 282-287. doi:10.1164/rccm.200608-1109OC

[12] Sokal, J.E. (1975) Editorial: Measurement of delayed skintest responses. The New England Journal of Medicine, 293, 501-502. doi:10.1056/NEJM197509042931013

[13] American Thoracic Society and the Centers for Disease Control and Prevention (2000) Diagnostic standards and classification of tuberculosis in adults and children. American Journal of Respiratory and Critical Care Medicine, 161, 1376-1395.

[14] Li, Y., Zhu, Y., Zhou, L., Fang, Y., Huang, L., Ren, L., Peng, Y., Li, Y., Yang, F., Xie, D., Tang, W., Zhang, N., Zhong, Q. and Lai, X. (2011) Use of HLA-DR*08032/E7 and HLA-DR*0818/E7 tetramers in tracking of epitopespecific CD4+ T cells in active and convalescent tuberculosis patients compared with control donors. Immunobiology, 216, 947-960. doi:10.1016/j.imbio.2011.01.003

[15] Ewer, K., Deeks, J., Alvarez, L., Bryant, G., Waller, S., Andersen, P., Monk, P. and Lalvani, A. (2003) Comparison of T-cell-based assay with tuberculin skin test for diagnosis of Mycobacterium tuberculosis infection in a school tuberculosis outbreak. Lancet, 361, 1168-1173. doi:10.1016/S0140-6736(03)12950-9

[16] Hill, P.C., Brookes, R.H., Fox, A., Fielding, K., Jeffries,
D.J., Jackson-Sillah, D., Lugos, M.D., Owiafe, P.K., Donkor, S.A., Hammond, A.S., Out, J.K., Corrah, T., Adegbola, R.A. and McAdam, K.P. (2004) Large-scale evaluation of enzyme-linked immunospot assay and skin test for diagnosis of Mycobacterium tuberculosis infection against a gradient of exposure in the Gambia. Clinical Infectious Diseases, 38, 966-973. doi:10.1086/382362

[17] Ferrara, G., Losi, M., D’Amico, R., Roversi, P., Piro, R., Meacci, M., Meccugni, B., Dori, I.M., Andreani, A., Bergamini, B.M., Mussini, C., Rumpianesi, F., Fabbri, L.M. and Richeldi, L. (2006) Use in routine clinical practice of two commercial blood tests for diagnosis of infection with Mycobacterium tuberculosis: A prospective study. Lancet, 367, 1328-1334. doi:10.1016/S0140-6736(06)68579-6

[18] Jackson-Sillah, D., Hill, P.C., Fox, A., Brookes, R.H., Donkor, S.A., Lugos, M.D., Howie, S.R., Fielding, K.R., Jallow, A., Lienhardt, C., Corrah, T., Adegbola, R.A. and McAdam, K.P. (2007) Screening for tuberculosis among 2381 household contacts of sputum-smearpositive cases in the Gambia. Transactions of the Royal Society of Tropical Medicine and Hygiene, 101, 594-601. doi:10.1016/j.trstmh.2007.02.001

[19] Guwatudde, D., Nakakeeto, M., Jones-Lopez, E.C., Maganda, A., Chiunda, A., Mugerwa, R.D., Ellner, J.J., Bukenya, G. and Whalen, C.C. (2003) Tuberculosis in household contacts of infectious cases in Kampala, Uganda. American Journal of Epidemiology, 158, 887-898. doi:10.1093/aje/kwg227

[20] Egsmose, T., Ang'awa, J.O. and Poti, S.J. (1965) The use of isoniazid among household contacts of open cases of pulmonary tuberculosis. Bulletin of the World Health Organ, 33, 419-433.

[21] Puffer, R.R., Zeidberg, L.D., Dillon, A., Gass, R.S. and Hutcheson, R.H. (1952) Tuberculosis attack and death rates of household associates; the influence of age, sex, race, and relationship. American Review of Tuberculosis, 65, 111-127.

[22] Ferebee, S.H. and Mount, F.W. (1962) Tuberculosis morbidity in a controlled trial of the prophylactic use of isoniazid among household contacts. The American Review of Respiratory Disease, 85, 490-510.

[23] Nienhaus, A., Schablon, A. and Diel, R. (2008) Interferon-gamma release assay for the diagnosis of latent TB infection-analysis of discordant results, when compared to the tuberculin skin test. PLoS One, 3, e2665. doi:10.1371/journal.pone.0002665

[24] Piana, F., Ruffo Codecasa, L., Baldan, R., Miotto, P., Ferrarese, M. and Cirillo, D.M. (2007) Use of T-SPOT. TB in latent tuberculosis infection diagnosis in general and immunosuppressed populations. New Microbiologica, 30, 286-290

[25] Pai, M., Zwerling, A. and Menzies, D. (2008) Systematic review: T-cell-based assays for the diagnosis of latent tuberculosis infection: An update. Annals of Internal Medicine, 149, 177-184. 